\title{
Putting the genie back in the bottle: protecting children from lead exposure in the 21 st century. A report from the field
}

\author{
Frances T Boreland ${ }^{a, b}$ and David M Lyle \\ a Broken Hill University Department of Rural Health, University of Sydney, Broken Hill, NSW, Australia \\ b Corresponding author: Frances.Boreland@health.nsw.gov.au
}

\section{Article history}

Publication date: November 2014

Citation: Boreland F, Lyle D. Putting the genie back in the bottle: protecting children from lead exposure in the 21st century - a report from the field. Public Health Res Pract. 2014;25(1):e2511403. doi: http:// dx.doi.org/10.17061/phrp2511403

\section{Key points}

- There is no safe level of lead exposure

- Blood lead levels among young children in Broken Hill are elevated due to mining and historical smelting activity in the area

- A multifaceted program in Broken Hill (1994-2001) reduced blood lead levels by two-thirds, but levels have remained stable since 2005

- Currently, $53 \%$ of children in Broken Hill exceed the draft National Health and Medical Research Council blood lead reference level $(5 \mu \mathrm{g} / \mathrm{dL})$

- A comprehensive abatement program is required to further reduce lead exposure

\section{Abstract}

This paper highlights progress on an important public health issue which, despite significant progress, has now stalled and is in need of renewed investment. The objective is to describe the effectiveness of efforts to reduce childhood lead exposure in Broken Hill - a historic mining town in western NSW - and what is required to further reduce exposure.

Lead has no known function in the human body, and emerging evidence suggests that no level of exposure is without health effects. A 1991 blood lead survey of 1-4-year-old children identified lead exposure as a significant public health issue in Broken Hill. A major NSW Government-funded program to reduce lead exposure began in 1994, and, by 2001, blood lead levels had reduced by two-thirds. The program was then integrated into other services and funding significantly reduced; blood lead levels have remained relatively unchanged since 2005. At present, 53\% of children in Broken Hill have blood lead levels above the recently released National Health and Medical Research Council draft reference value for lead. Participation in annual blood lead screening declined from $52 \%$ to $38 \%$ after project funding decreased, but recent changes have doubled participation rates.

A comprehensive abatement program is required to further reduce lead exposure in this community, and further research is required into how to maintain low blood lead levels and how best to engage the community about reducing individual lead risks. Findings from such studies would be relevant to the broader Australian community.

\section{Introduction}

This report chronicles public health efforts to deal with lead in Broken Hill, and calls for renewed action to systematically reduce lead exposure among young children in the town.

Lead has been recognised as a toxin since at least Roman times ${ }^{1}$, and has no known function in the human body. ${ }^{2}$ Health effects depend on age, blood lead level and the amount of time a person has been exposed. Young children are 
most at risk because their brains and nervous systems are still developing and are vulnerable to the effects of lead. ${ }^{2}$ Very high blood lead levels cause convulsions, coma and sometimes death. Moderate blood lead levels are associated with a range of effects, including anaemia, reduced kidney and nerve function, and increased blood pressure. Low blood lead levels (below $10 \mu \mathrm{g} / \mathrm{dL}$ ) are associated with increased risk of behavioural problems among children, delayed onset of puberty, and increased risk of hypertension in adults and pregnant women. ${ }^{2}$

At the blood lead levels usually seen in industrialised countries today, the biggest concern is associated with the adverse impact of lead on the IQ of young children - which may be irreversible - and the increased risk of learning difficulties. ${ }^{2}$ In recent years, evidence has accumulated to suggest that no level of lead exposure is safe. ${ }^{3}$ There is increasing emphasis on preventing children from being exposed to lead at all ${ }^{3,4}$, both to prevent potential harm and because it can be difficult to reduce blood lead levels once they have risen, especially if children have been exposed to lead over a long time. . $^{5,6}$

Germany ${ }^{3}$, the $\mathrm{US}^{7}$ and Canada ${ }^{8}$ have recently reduced their blood lead reference values for children (the level considered a 'background level' above which sources of exposure should be investigated) to $5 \mu \mathrm{g} / \mathrm{dL}$ of blood or lower; the National Health and Medical Research Council (NHMRC) recently released a discussion paper recommending that the reference level for the general Australian population be reduced to $5 \mu \mathrm{g} / \mathrm{dL}{ }^{2}$ It is estimated that 100000 Australian children have blood lead levels at or above $5 \mu \mathrm{g} / \mathrm{dL} .{ }^{4}$

In Australia, blood lead levels have declined significantly since lead was removed from petrol and household paint, and regulations were introduced to restrict or prevent the use of lead in consumer goods, medicines and imported products. ${ }^{2}$ People can still be exposed to lead from old lead-based paint that is in poor condition or disturbed during renovations, and communities close to lead-based industries or in areas that had high traffic volumes before lead was removed from petrol are also at greater risk of exposure via contaminated soil and dust. 2,6,9 Other sources of lead in Australia include imported products (e.g. jewellery, cosmetics, 'traditional' medicines, toys with leadbased paint) and household objects (e.g. food or drink containers made of lead crystal or pewter, ceramic cookware, old pipes and plumbing fittings, solder, old iron enamelled bathtubs, fishing sinkers, curtain weights). ${ }^{2}$

\section{Broken Hill}

Silver, lead and zinc have been mined in Broken Hill since 1884, and the ore was smelted onsite for the first 15 years. ${ }^{10}$ The mines, smelters and waste dumps occur within a zone of mining activity known locally as the 'Line of Lode', which bifurcates the city. Homes are built within walking distance of the mines; residential backyards lie adjacent to the southern boundary of the mines and some homes are located on the mining leases. The smelters were recognised as appalling even by the standards of the day ${ }^{11}$, and are estimated to have emitted up to 46,400 tonnes of lead into the atmosphere. ${ }^{12}$ Periodic reworking of the mine waste dumps as better extraction techniques became available also contributed to the dispersal of lead ${ }^{12}$, which is now widespread in soil and dust; levels are highest close to and downwind of the zone of mining activity. ${ }^{13}$

In addition, a large proportion of Broken Hill homes were built before1970 (before lead was taken out of paint), and ceilings of older homes are commonly made of pressed tin or fine fluted corrugated iron, making them harder to seal against dust entry. The semi-arid climate facilitates the movement of contaminated soil and dust. Isotopic analysis has shown that the ore body, paint and petrol are all important sources of lead in both dust and blood, with the importance of ore-body lead increasing with proximity to the Line of Lode. ${ }^{14}$

Although lead was recognised as a health problem for miners and their families within a few years of the mines being established ${ }^{11}$, occupational health and safety issues were the main concern. A combination of better work practices, transferring smelting to Port Pirie, mining at deeper levels and extracting less dusty ore resulted in miners no longer suffering lead poisoning. ${ }^{15,16}$ Lead became an issue of broader concern in the community during the 1970s due to a combination of surface mining restarting and reworking of the waste dumps. However, a survey of non-occupationally exposed people (including children of primary school age) found no-one with blood lead levels above the then level of concern $(40 \mu \mathrm{g} / \mathrm{dL}){ }^{16}$

Despite this, there continued to be indications that lead may be a public health concern in Broken Hill through the 1980s and 1990s, including high blood lead levels among local dogs ${ }^{17}$, three babies born with delayed visual maturation within an 18-month period (which was attributed to lead exposure by local physicians $\left.{ }^{18}\right)$, and findings of high lead levels in water tanks ${ }^{19}$ and ceiling dust in local homes. ${ }^{14}$

\section{Management of lead in Broken Hill}

\section{$1991-2001$}

In response to increasing community concern, a blood lead survey of 1-4-year-old children was undertaken in 1991, which found that a quarter of children had blood lead levels above the then level of concern (25 $\mathrm{\mu g} / \mathrm{dL}) .{ }^{19}$ The sources and pathways of lead exposure were investigated ${ }^{14,19}$, and in 1994, a major NSW Government-funded program (the Broken Hill Lead Management Program) was established to reduce children's blood lead levels.

The program was funded directly from NSW Treasury through the Health Department and Environment Protection Authority (EPA), and was overseen by a 
Steering Group consisting of Health Department and EPA representatives, and informed by a Community Working Party that included the local council, unions, mines, water board and local community representatives. The program consisted of screening, case finding, active case management (including a trial remediation of the homes of children with high blood lead levels), public education, and some remediation of publicly accessible areas such as footpaths, vacant blocks and playgrounds that had high soil lead levels. The whole program was supported through evaluation. ${ }^{9}$

During this time, significant remediation works were also funded and undertaken by industry - the waste dumps and railway goods yards in the centre of town were capped to reduce dust, and major stormwater control works were done to prevent discharge of contaminated sediment into adjacent streets. Airborne lead reduced significantly in the late 1990s, and the reductions were greatest closest to the mines..$^{20}$

Average blood lead levels reduced steadily from $16.7 \mu \mathrm{g} / \mathrm{dL}$ in 1991 to $7.6 \mu \mathrm{g} / \mathrm{dL}$ in $2001 .{ }^{21}$

\section{1-08}

In 2001, the Lead Management Program was integrated with mainstream services in an effort to ensure its sustainability. It went from functioning from a stand-alone building with a clear identity in town to being part of a larger organisation, the Child and Family Health Centre (CFHC). Funding decreased significantly, and dedicated funding to a stand-alone unit finished at the end of 2006, although specific funding to cover blood lead surveillance and lead management activities continued. The Steering Group and Working Party were disbanded. Screening and educational activities were provided through the CFHC, but there was minimal practical support for families of children with high blood lead levels if they could not afford recommended measures to reduce their child's exposure, such as putting down clean soil, sealing gaps and cracks, and stabilising lead-based paint. This is problematic, given the high level of disadvantage in Broken Hill. ${ }^{22}$

Lead management was integrated somewhat into the activities of other relevant organisations. The local council incorporated lead into development applications and noted lead on 149 planning certificates; the water authority produced a pamphlet about living safely with lead while being water-wise, and during the recent drought, did not introduce water restrictions in Broken Hill because of the recognised need to maintain a lead-safe environment.

From the community's point of view, these changes meant that lead was no longer visible to the local community, and this was interpreted to mean that lead was no longer a problem, or no longer a government priority, or both. ${ }^{23}$ Annual participation in blood lead screening steadily decreased, from $52 \%$ in 2005 to $38 \%$ in 2008. ${ }^{21}$
Average blood lead levels continued to decline, albeit more slowly, from $7.6 \mu \mathrm{g} / \mathrm{dL}$ in 2001 to $4.9 \mu \mathrm{g} / \mathrm{dL}$ in $2008 .{ }^{21}$ From 2002, blood lead levels of children living closest to the mines decreased to levels similar to that of children living in other parts of town. ${ }^{20}$

\section{8-13}

In response to the declining screening participation, a new Health Steering Group was established, consisting of representatives from local health service organisations, the Western NSW Population Health Unit and the Broken Hill University Department of Rural Health (BHUDRH). This group commissioned two community consultations, which found several factors contributing to a decline in screening ${ }^{23}$ :

- The method of screening (venous blood tests)

- Limited access to screening facilities (screening was available one day per week)

- The perception that lead was no longer important

- The fact that minimal help was available if children did have high blood lead levels.

In light of these findings, finger-prick point-of-care testing was introduced in October 2008, and screening was offered with routine health checks at the local Aboriginal Health Service from 2010, and when children attended for immunisation at the CFHC from 2011. Screening attendance has since doubled. ${ }^{21}$

The Steering Group recognised the importance of broader community involvement, and approached the local council to establish a new Lead Reference Group (LRG), which was established in September 2008. The LRG consists of representatives from relevant state and local authorities, industry and community representatives. The group meets quarterly, has developed a strategic plan from which organisations can incorporate relevant activities into their own business plans and provides a forum for sharing relevant information.

Between 2008 and 2013 the program continued to consist largely of screening and advice. ${ }^{23}$ Average blood lead levels have fluctuated between $4.9 \mu \mathrm{g} / \mathrm{dL}$ in 2008 and $5.6 \mu \mathrm{g} / \mathrm{dL}$ in $2013^{21}$, although it is unclear whether the increase in screening participation means that the latest figure (5.6) may have been a true representation of the mean over this time.

\section{Current status}

Since 2005, average blood lead levels have varied between $4.7 \mu \mathrm{g} / \mathrm{dL}$ and $5.9 \mu \mathrm{g} / \mathrm{dL} .{ }^{21}$ Broken Hill children still have blood lead levels that are at least twice that of Sydney children a decade ago ${ }^{20} ; 21 \%$ of $1-4$-yearolds exceed the rescinded Australian blood lead goal $(10 \mu \mathrm{g} / \mathrm{dL})$ and $53 \%$ have levels above the draft NHMRC reference value of $5 \mu \mathrm{g} / \mathrm{dL}$. ${ }^{2,21}$ It should be noted that the NHMRC $5 \mu \mathrm{g} / \mathrm{dL}$ value is the trigger for investigation of environmental sources of lead and tailored advice on avoiding lead exposure; it is not a threshold for 
'lead poisoning'. Importantly, Aboriginal children have consistently had lead levels that are $2-3 \mu \mathrm{g} / \mathrm{dL}$ higher than the non-Aboriginal population, and are twice as likely to have blood lead levels that exceed $10 \mu \mathrm{g} / \mathrm{dL} .{ }^{21}$

Lead is now back on the local agenda - a new lead mascot has been launched and a website is being developed to provide a 'one stop shop' for lead information (www.leadnsw.com.au). The LRG is supporting work by several university final-year and PhD students investigating various aspects of lead contamination. A lead guide has been developed for local general practitioners, and the BHUDRH is supporting a PhD project to evaluate aspects of local lead management. The community, community groups, utilities and health and government agencies recognise that lead is a significant public health issue for young children, and there is frustration that the issues are not able to be addressed fully due to lack of funding. ${ }^{23,24}$

\section{Future directions and conclusions}

Despite significant improvement since 1991, blood lead levels among young children in Broken Hill are still too high. A much stronger focus on preventing lead exposure is required to reduce blood lead levels further. Public health principles suggest that reducing overall population exposure by placing an effective barrier between the community and the lead is the most effective strategy, and this is supported by studies showing the effectiveness of thorough and systematic control of lead in soil, paint and dust for protecting children from lead exposure. ${ }^{25,26}$ Local studies confirm that remediation has significantly decreased lead levels in homes that had high lead levels and is a useful part of an overall prevention strategy. ${ }^{27}$ Education and changing cleaning habits are not effective unless the sources and pathways of exposure are also controlled. ${ }^{28}$

Although lead is widespread in soil and dust in Broken Hill, it is likely that most of the community exposure arises from 'legacy lead' - that is, from re-entrainment and redistribution of lead that has already escaped from the ore body, or petrol and lead paint that is unstable or disturbed during renovations. Lead emissions from both mines located within the town are consistently within their regulatory requirements and are a fraction of the estimated historical emissions. ${ }^{12,29,30}$ There is thus a good chance that, if lead is thoroughly cleaned up, blood lead levels in young children will fall again.

A major abatement program that systematically identifies and cleans up remaining lead hotspots (including housing) would significantly reduce childhood lead exposure in Broken Hill. Resources are required for increased community outreach and education, as this is currently restricted to children with very high blood lead levels (20 $\mathrm{gg} / \mathrm{dL}$ and higher). Funding is also required to assist with basic risk reduction activities (such as putting down clean soil) in the homes of children with high blood lead levels where families cannot undertake these activities themselves. Further research is required to determine factors associated with children maintaining blood lead levels below $5 \mu \mathrm{g} / \mathrm{dL}$, and how best to engage the community about reducing individual lead risks. Findings from such studies would also be relevant to the broader Australian community.

It is possible to put this particular genie back in its bottle. It is time to act.

\section{Competing interests}

Frances Boreland was a Technical Officer with the Broken Hill Lead Management Program from 1994 to 2000 and has evaluated aspects of lead management in Broken Hill since 1996. She has been a member of the Broken Hill Lead Reference Group and Lead Steering Group since 2008.

David Lyle has been involved with evaluating aspects of lead management in Broken Hill since 1994. He has been a member of the Broken Hill Lead Reference Group and Lead Steering Group since 2008.

\section{References}

1. Hernberg S. Lead poisoning in a historical perspective. Am J Ind Med. 2000;38:244-54.

2. National Health and Medical Research Council. Draft information paper: evidence on the effects of lead on human health. Canberra: National Health and Medical Research Council; 2014.

3. Wilhelm M, Heinzow B, Angerer J, Schulze, C. Reassessment of critical lead effects by the German Human Biomonitoring Commission results in suspension of the human biomonitoring values (HBM I and HBM II) for lead in blood of children and adults. Int J Hyg Envir Heal. 2010;213:265-9.

4. Taylor MP, Winder C, Lanphear BP. Eliminating childhood lead toxicity in Australia: a call to lower the intervention level. Med J Australia. 2012;197(9):493.

5. Hilts SR. Effect of smelter emission reductions on children's blood lead levels. Sci Total Environ. 2003;303:51-8.

6. Maynard E, Thomas R, Simon D, Phipps C, Ward C, Calder I. An evaluation of recent blood lead levels in Port Pirie, South Australia. Sci Total Environ. 2003;303:25-33.

7. Centers for Disease Control and Prevention. Response to the advisory committee on childhood lead poisoning prevention report, low level lead exposure harms children: a renewed call for primary prevention. Atlanta: Centers for Disease Control and Prevention; 2012.

8. Health Canada. Risk management strategy for lead. Ottawa: Minister of Health; 2013. 
9. Lyle DM, Phillips AR, Balding WA, Burke H, Stokes D, Corbett S, et al. Dealing with lead in Broken Hill - trends in blood lead levels in young children 1991-2003. Sci Total Environ. 2006;359:111-19.

10. Solomon RJ. The richest lode, Broken Hill: 1883-1988. Sydney: Hale and Iremonger; 1988.

11. Thompson AJ. Report of board appointed to inquire into the prevalence and prevention of lead poisoning at the Broken Hill silver-lead mines. Sydney: NSW Legislative Assembly; 1893.

12. Van Alphen M. The history of smelting and ore dressing in Broken Hill and the potential for mine derived lead contamination in Broken Hill. Adelaide: M Van Alphen; 1991.

13. Boreland F, Lyle DM, Wlodarczyk J, Balding WA, Reddan S. Lead dust in Broken Hill homes - a potential hazard for young children? Aust NZ J Publ Heal. 2002;26:2037.

14. Gulson BL, Mizon KJ, Law AJ, Korsch MJ, David JJ, Howarth D. Sources and pathways of lead in humans from the Broken Hill mining community. Part 1: Lead isotope fingerprinting. Canberra: Division of Exploration and Geoscience, Commonwealth Scientific and Industrial Research Organisation; 1993.

15. Kearns RHB. Broken Hill 1894-1914. Volume 2: The uncertain years. Adelaide: Openbook Publishers; 1974.

16. Woodward-Clyde Pty Limited. Evaluation of environmental lead at Broken Hill.1993. Sydney: AGC Woodward Clyde Pty Ltd; 1993.

17. Koh TS, Babidge PJ. A comparison of blood lead levels in dogs from a lead mining, lead smelting, urban and rural island environment. Aust Vet J. 1986;63(9):282-5.

18. Gulson BL, Yui LA, Howarth D. Delayed visual maturation and lead pollution. Sci Total Environ. 1998;224:2159.

19. Phillips A. Trends in and factors for elevated blood lead concentration in Broken Hill pre-school children in the period 1991-1993. Newcastle (NSW): University of Newcastle; 1998.

20. Boreland F, Lesjak M, Lyle D. Managing environmental lead in Broken Hill: a public health success. NSW Public Health Bull. 2008;19(9-10):174-9.

21. The Child \& Family Health Service. Lead - it's in our hands: blood lead testing. Broken Hill (NSW): Broken Hill Health Service, Far West Local Health District, NSW Health; 2014 [cited 2014 Jul 30]; Available from: www. leadnsw.com.au/\#!blood-lead-testing/czyz
22. Australian Bureau of Statistics. ABS releases measures of socio-economic advantage and disadvantage. Canberra: Australian Bureau of Statistics; 2008 [cited 2014 Sep 4]. Available from: www.abs.gov.au/ ausstats/abs@.nst/mediareleasesbyReleaseDate/ AC5B967F97D4902ECA257B3B001AF670

23. Kardamanidis K, Lyle D, Boreland F. Environmental lead management in Broken Hill: addressing decreasing blood lead screening rates. NSW Public Health Bull. 2008;19(910): 1802.

24. Gough N, Lesjak M, Kirby S, Party TBHACW, Lyle D. The impact of lead and a change of lead guidelines for Broken Hill: an inquiry into community concern and desire for action. Broken Hill (NSW): Broken Hill University Department of Rural Health (UDRH); 2012. Located at: Broken Hill UDRH Library, Broken Hill, NSW.

25. Lanphear BP, Dietrich KN, Berger O. Prevention of lead toxicity in US children. Ambul Pediatr. 2003;3(1):27-36.

26. Mielke HW, Covington TP, Mielke PWJ, Wolman FJ, Powell ET, Gonzales CR. Soil intervention as a strategy for lead exposure prevention: the New Orleans leadsafe childcare playground project. Environ Pollut. 2011;159(89):2071-7.

27. Boreland F, Lyle DM. Lead dust in Broken Hill homes: effect of remediation on indoor lead levels. Environ Res. 2006;100:276-83.

28. Yeoh B, Woolfenden S, Wheeler D, Alperstein G, Lanphear B. Household interventions for preventing domestic lead exposure in children. Cochrane DB Syst Rev. 2012;4:1-63.

29. CBH Resources Limited. Annual environment management report. North Sydney (NSW): $\mathrm{CBH}$ Resources Limited; 2013 [cited 2014 Jun 6]. Available from: www.cbhresources.com.au/files/3413/7757/8867/ AEMR_April_12_March_13_Updated_13_8_13.pdf

30. Perilya. Monthly environmental report, April 2014. Adelaide: Perilya; 2014 [cited 2014 June 6]. Available from: www.perilya.com.au/articles/april-2014-report1/ April_2014_Report1.pdf

\section{Copyright: (C) (7)(2)}

(C) 2014 Boreland and Lyle. This article is licensed under the Creative Commons Attribution-NonCommercial-ShareAlike 4.0 International License, which allows others to redistribute, adapt and share this work non-commercially provided they attribute the work and any adapted version of it is distributed under the same Creative Commons licence terms. See: http://creativecommons.org/licenses/by-nc-sa/4.0/ 